456 Beard.-Reproduction in Animals and Plants.

\title{
On the Phenomena of Reproduction in Animals and Plants.
}

The Conjugation of the Infusoria and the Meaning of the Processes Involved.

BY

J. BEARD.

With Woodcuts 9-13.

IT has been specially interesting to study the conjugationprocesses of this group in the light of experiences formed elsewhere. As is well known, the facts have not been gleaned without the arduous labours of many distinguished investigators. The processes appear to be difficult of observation, but, thanks to the brilliant work of R. Hertwig ${ }^{1}$ and E. Maupas ${ }^{2}$, our knowledge of them has advanced enormously in recent years.

It may appear presumptuous to offer an explanation of the meaning of the very complicated process, but, if apology be called for, it may rest on the ground that it appeared necessary to put the theoretical 'law of reproduction' to the test in this case also. If it sufficed as an explanation of the facts, so much the better; if it were found wanting, so much the worse.

1 Hertwig, R., Ueber die Conjugation der Infusorien. Abhandl. d. bayer. Akad. d. Wiss., II. Cl., Bd. XVII, I889.

${ }^{2}$ Maupas, E., Le rajeunissement karyogamique chez les ciliés. Arch. de Zool. expér. ze série. T. vii, 1889 . 
The one fact that would be fairly decisive appears to be lacking, or, at any rate, incompletely known. This is as to the precise point at which the chromatin-reduction takes place.

Theoretically, as will be presently proved, such a reduction at some point or other must be postulated even here. However, from R. Hertwig's statements the actual point can be fixed upon with a fair degree of certainty, and, as will be evident, it would appear to lie at a certain phase of the conjugation which a priori seems to be a very likely one.

Amoeba, Gregarina, \&c.-in fact a great many far simpler Protozoa than Paramecium, apart from fission, exhibit a simple process of conjugation, leading to encystment and spore-formation. Such a process, however simple it may be, must entail a reduction of chromosomes prior to the next conjugation.

Although there appear to exist no direct observations on such a reduction in these cases, there is practically no doubt that it takes place at the spore-formation following conjugation and encystment. Otherwise the spore-formation would be without meaning; for these forms can multiply in a very rapid manner by simple fission alone. Such a conjugation as the above must be a very primitive form of an alternation, and, indeed, one in which a zygote or gametozooid hardly can be said to possess a separate existence for any lengthy period; because the spore-formation and reduction follow almost immediately on the conjugation and duplication.

Paramecium is morphologically a far more complex organism. It presents more than one nucleus, and division of labour among these. As in $A m o e b a$, we recognize here two processes of multiplication-fission and conjugation ${ }^{1}$.

Colpidium colpoda (woodcut 9) is usually cited as affording one of the simplest examples of conjugation, and it may therefore be the first form to be examined.

Turning our attention to the processes that occur after

${ }^{1}$ Spore-formation is not a distinct and separate mode of reproduction, but is a necessary corollary to conjugation. 


\section{$45^{8}$ Beard.-Reproduction in Animals and Plants.}

conjugation $(f g h)$ we find that these are all simple fissions, and they are bound up, as E. Maupas has demonstrated, with differentiations of nuclei into nutritive and reproductive, and the formation of new individuals by fission.

There are no abortive products, and there is no evidence of spore-formation subsequent to the conjugation.

Developmental processes which appear to be nonsensical have usually a deep significance. The morphologist who encounters such ought always

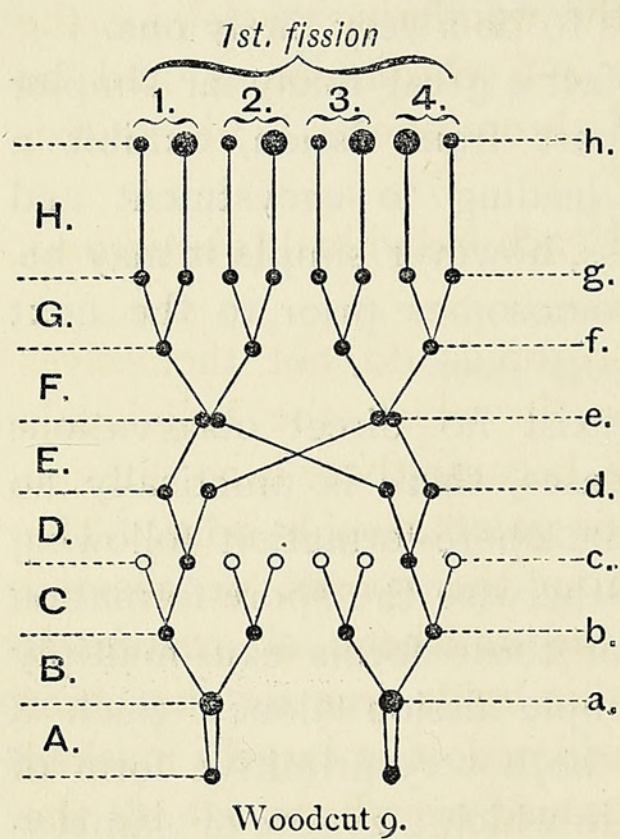

Colpidium colpoda (after Maupas). to suspect that there is something in them requiring close attention.

Apparently meaningless processes having, as O. Hertwig observes, a striking similarity to the formation of the polar bodies during oogenesis, are seen in the changes $(b c)$ which take place in the micronucleus prior to the actual act of conjugation.

Now, the only reproductive products with which we are acquainted are gametes, including eggs and sperms, and spores. At the stage $c$ there are a number of nuclei formed, resulting from the two mitotic divisions $\mathrm{B}$ and $\mathrm{C}$. In this particular species, Colpidium colpoda, three of the four $(c)$ in each of the conjugating individuals are abortive. Do these cell-nuclei represent gametes? The answer to this appears to be in the negative; they do not conjugate. Before an actual conjugation happens, each of the functional ones again divides, and the products are those which furnish the actual materials for the conjugation, i.e. the gametes. (In this latter division, D, we have really a virtual fission of sporozooids to form like conjugating gametes.) 
The pole-nuclei must therefore be spores, and the process, i.e. the two divisions at $\mathrm{B}$ and $\mathrm{C}$, must be a spore-formation. The proof of this would undoubtedly be the discovery that in these two divisions-probably in the second one-a reduction of the number of chromosomes was accomplished.

The evidence that this happens is at present not quite complete. In Paramecium, where, as will be seen, quite similar processes occur (woodcuts IO and II, B and C), it is certain that prior to conjugation a reduction does occur. R. Hertwig ${ }^{1}$ states that the stationary and the wandering nuclei, i.e. the like gametes $(d)$, possess each 4-6 chromosomes, and he describes the normal number of chromosomes in the micronucleus of $P$. aurelia as ten ${ }^{2}$.

Of the four spores produced in each individual (Colpidium), all but one atrophy.

The spore-individuals or sporozooids do not themselves conjugate, but by virtual fission, in which the individuals produced do not become separate, because there is no division of the protoplasm, like gametes or gametozooids arise. The sexual generation thus arises from the spores, or asexual generation, by fission ${ }^{3}$. Thus the antithetic alternation is recognizable here; but, and all this holds true for the other Infusorians to be afterwards considered, it is largely masked to observation and detection, because overshadowed by the process of fission, which has become so highly evolved among the Infusoria.

Other Infusoria present slight differences in the conjugation processes, and, in order to demonstrate how, mutatis mutandis, the 'law' holds for all, short interpretations of various cases, figured by Maupas and worked out by him and by R. Hertwig, may now follow.

Paramecium aurelia (woodcut 10 ). This form possesses two micronuclei. The conjugation is explained as follows.

1 Loc. cit., p. 182.

${ }^{2}$ Loc. cit., p. 184 .

3 Subsequent to actual conjugation the cycle contains a great but, as Maupas has proved, definite number of secondarily asexual generations, but with duplicated chromosomes, produced by fissions. 
460 Beard.-Reproduction in Animals and Plants.

I. A to C. Two divisions of micronuclei leading to sporeformation $(c)$ and reduction. Atrophy of seven of the eight spores.

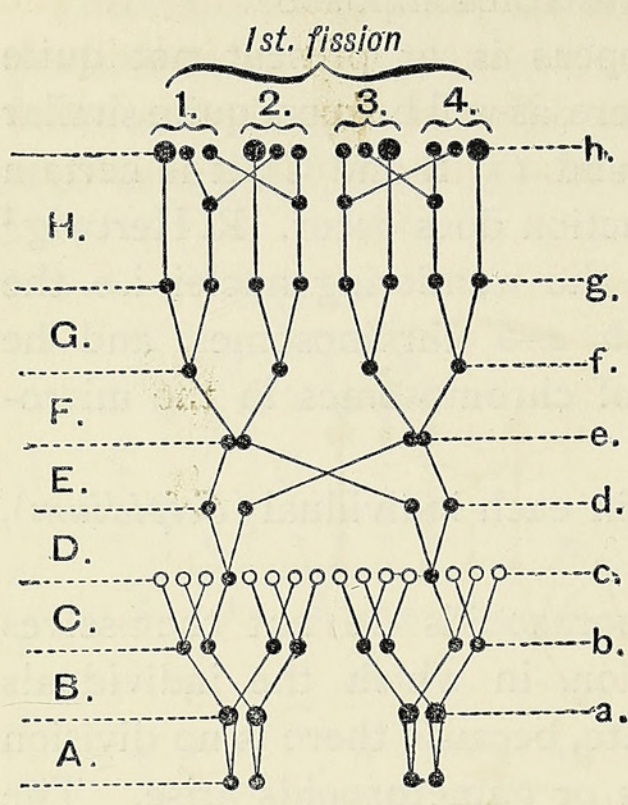

Woodcut Io.

Paranecium aurelia (after Maupas.)

2. D. Fission of the spores or sporozooids to form like gametes $(d)$.

3. E. Conjugation of the gametes $(e)$.

4. $f, g$, and $h$. Formation and differentiation of new individuals from the zygote by fission consequent on conjugation.

Paramecium caudatum (woodcut II). Prior to conjugation there are, as in $P$. aurelia, two divisions of the micronucleus, which is here single.

I. B, C. Two divisions resulting in the formation of four spores $(c)$ and reduction. Abortion of three spores.

2. D. Fission of the spore-individuals to form like gametes.

3. Conjugation $(e)$ of the gametes.

4. F to $\mathrm{H}$. Fission leading to the formation and differentiation of new individuals subsequent to conjugation, but with abortive individuals or nuclei (macro- or micronuclei after $\frac{G}{2}$ at $h)^{1}$.

Onychodromus grandis (woodcut I2). The conjugation here, as made out by Maupas ${ }^{2}$ in a fashion that can only excite admiration, is exceedingly interesting and complicated. There are two micronuclei, and of these one, after commencing the steps leading to spore-formation and reduction, aborts $(b)^{3}$.

\footnotetext{
1 Probably micronuclei.

${ }^{2}$ Maupas, E., loc. cit., pp. $238-263$.

${ }^{3}$ Abortion of virtual spore-daughter-cells.
} 
The other accomplishes the spore-formation and reduction, but only two of the spores produced atrophy $(c)$. The other two in each individual form four like gametes by two fissions, and of these gametes two only are of functional use $(d)$. The other two abort $(d)$. After the conjugation, owing to the peculiar manner in which the macro-nuclei of new individuals are developed-in a mode quite different from that in which they arise in $P$. aurelia (a form also with two micronuclei)-

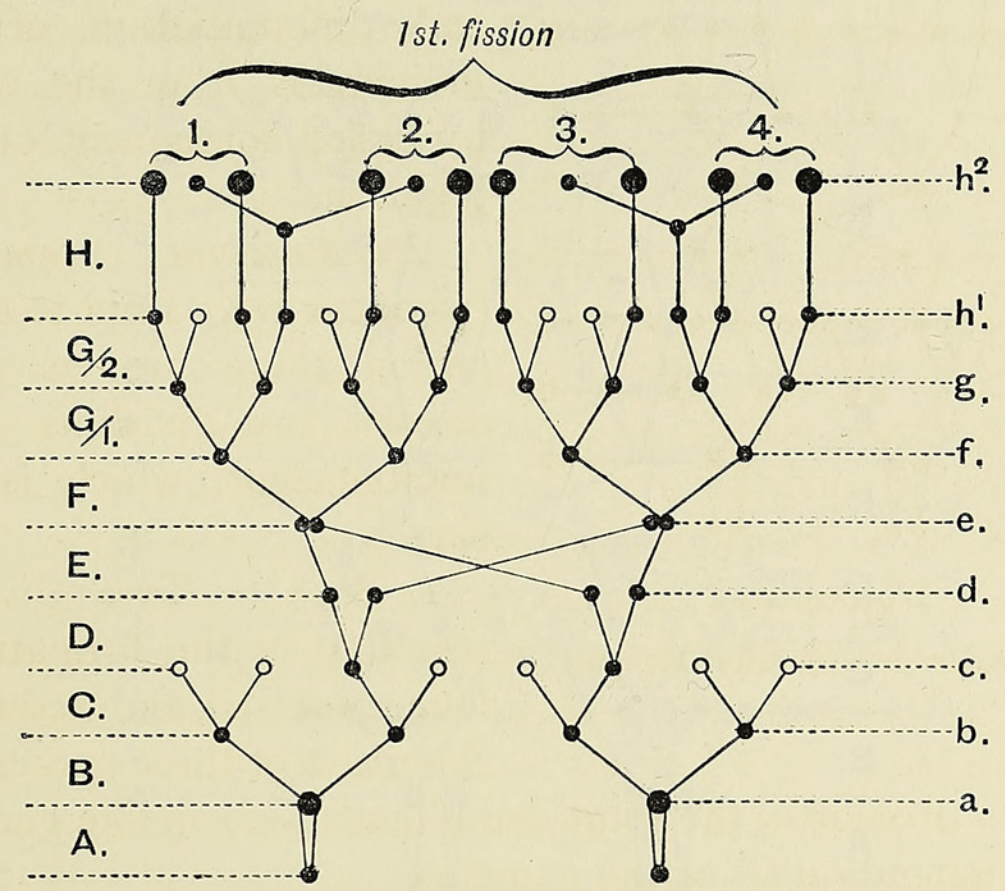

Woodcut II.

Paramecium caudatum (after Maupas).

there is again a nuclear atrophy $(g)$. This is obviously due to the fact that, after the first virtual fission subsequent to conjugation, the one nucleus is specialised to form micro-nuclei, the other to give rise to macro-nuclei only. To the species as it at present exists, the one macro-nuclei-forming element has become superfluous, but, though useless, like so many abortive vestigial structures, it must still invariably be formed, because the useful and functional one could not otherwise arise.

The form just considered presents quite sufficient com$\mathrm{K} \mathrm{k}$ 
462 Beard.-Reproduction in Animals and Plants.

plications in the processes which result in the building up of new individuals after the conjugation, but in the next and final one (Vorticella, woodcut ${ }_{13}$ ) these are met with in a yet more exaggerated form, and other amazing things happen prior to the conjugation. The reader may be reminded of what most of these are due to, i.e. to the differentiation of the conjugating individuals into macro-zooids and micro-zooids. The terms

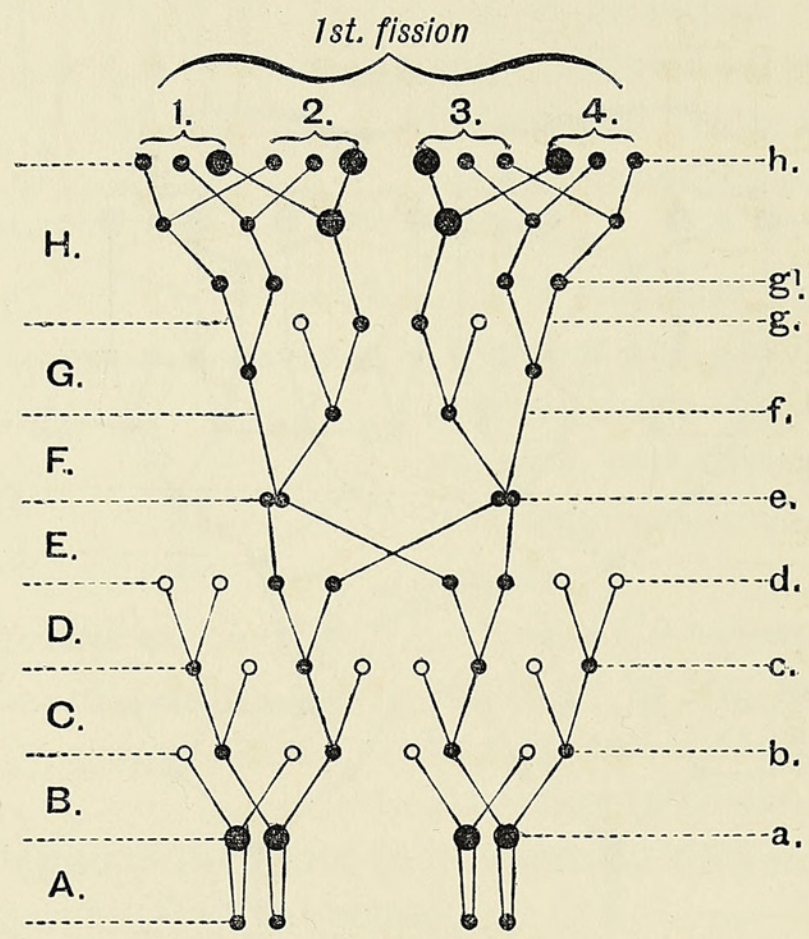

Woodcut I 2.

Onychodromus grandis (after Maupas).

macro- and micro-gametes used by Maupas are misnomers, for, as other instances have made evident, the individuals which are present at the beginning of the union culminating in conjugation are not really the conjugating forms. The true gametes are formed later on within, and as descendants of, the 'micro-' and 'macro-gamete.' The differentiation into these can hardly be said to affect the conjugating gametes; the latter are alike, as in other cases, and do not differ in form, as Maupas has shown. It would be incorrect to term 
the 'micro-' and 'macro-gametes' male and female respectively. This is something which should be reserved for the terminology of Metazoan individuals, where the gametes differ in form, although they are, as demonstrated by Boveri and O. Hertwig, morphologically equivalent. In other words we are not entitled to speak of sex in the Infusoria hitherto investigated.

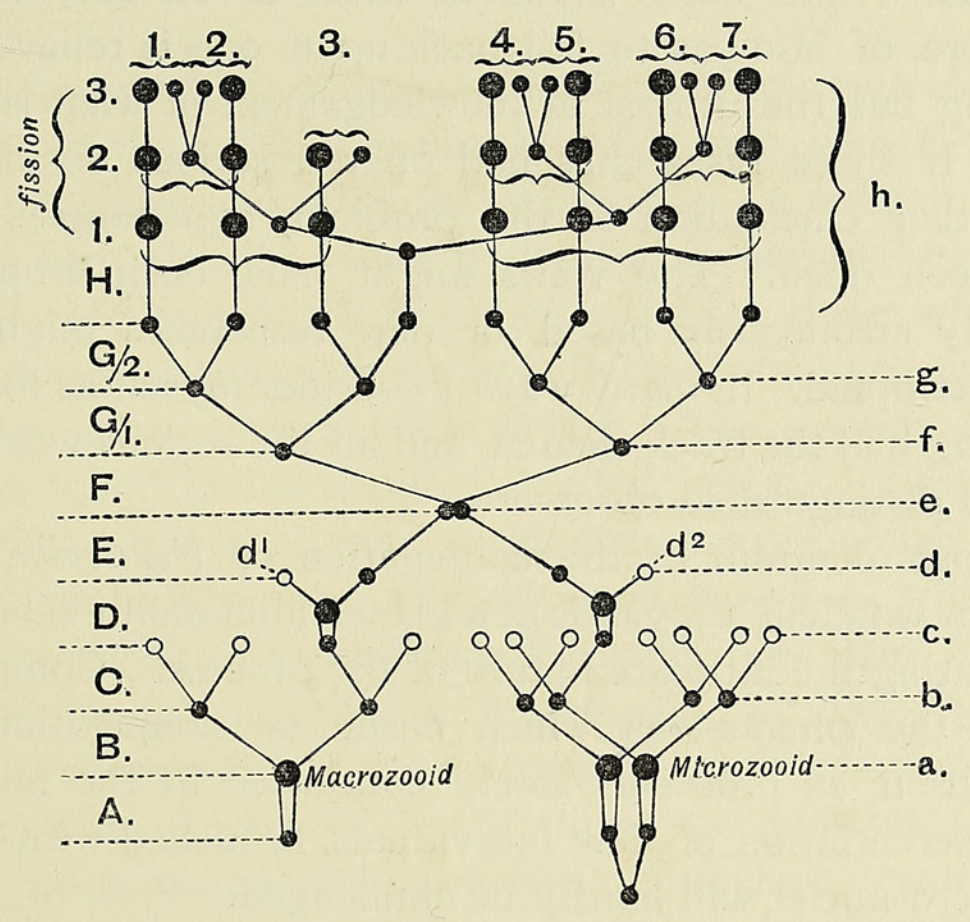

Woodcut I3.

Vorticella (after Maupas).

Before venturing on an interpretation of the whole process in Vorticella, I should like to pay a tribute of admiration to Maupas' brilliant researches. They stand out prominently among the published results of recent years as marvels of patience, exactitude, and morphological insight. It is a somewhat painful position to find one's self in, that of attempting to take a little of the cream from other people's researches. Some slight excuse may perchance be found in the circumstances that several years of my life have been devoted to the solving of this puzzle of the mode in which $\mathrm{K} \mathrm{k} 2$ 


\section{Beard.-Reproduction in Animals and Plants.}

animal development is accomplished, and that the alternation solution has been persistently stuck to, in spite of the fact that it was almost universally ignored, or, where noticed, looked upon as absurd.

My own researches have been sufficiently laborious and costly in time and money, without the additional burden of new investigations into, for instance, the conjugation of the Infusoria. With such works as those of R. Hertwig, and still more, of Maupas to fall back upon, one is relieved from anything but the utmost acknowledgement of what is due to them. If these researches had offered serious obstacles to the further elucidation of the problem, two courses would have been open. The views might have been dropped as probably erroneously based, or new researches might have been attempted. In many ways I consider myself as fortunate in having had the track cleared, and all the serious work done, by such distinguished observers.

Maupas' diagram of the conjugation of Vorticella, reproduced in woodcut $\mathrm{I}_{3}$, yields at a glance abundant evidence demonstrating the intricate nature of the process. Complicated as are the phenomena which ensue on conjugation, their explanation, as processes solely concerned in the formation and differentiation of new individuals, furnished with macroand micro-nuclei, will hardly be challenged.

The two divisions $\mathrm{B}$ and $\mathrm{C}$ of the micro-nucleus of the ' macro-gamete' are also simply explicable, for they differ in no respects from corresponding ones leading to spore-formation and reduction in other forms. Of the four spores $(c)$ produced three are abortive, whilst the fourth, representing the sporozooid, divides (D) as in other cases, once. Owing to the circumstance that the other individual, the micro-zooid, has become reduced in size, and has lost all power of receptivity for a conjugating gamete, the one $\left(d^{1}\right)$, which in the ancestry performed the functions of a 'wandering nucleus' passing over to what is now the micro-zooid, no longer possesses functions and undergoes atrophy. It is still formed, because its formation is a necessary incident in the 
origin of the functional one. This abortive gamete $\left(d^{1}\right)$ corresponds, if anything in the conjugation of the Infusoria does so, to one of the polar bodies formed in oogenesis, i.e. as a rudimentary gamete. It will be noted that it also has its abortive equivalent in the micro-zooid $\left(d^{2}\right)$. Regarding the phenomena in the latter prior to actual conjugation, an apparent stumbling-block is met with in the fact of the occurrence of three divisions of the micro-nucleus instead of two.

There might have been some hesitation in explaining away the first of these, were it not that Maupas, who is justified more than any one else in expressing an opinion on the matter, had already given a verdict favourable to all my desires. He regards the first division of the three, which also happens in both the conjugating individuals of Euplotes patella, as a formation of two micro-nuclei. The reasons assigned may be found in his memoir as cited below ${ }^{1}$. Leaving the first division out of account, as Maupas has also done, we have then in the micro-zooid two divisions $\mathrm{B}$ and $\mathrm{C}$, which may be interpreted as spore-formation and reduction. Of the eight spores $(c)$ only one is functional. It, like the corresponding sporo-zooid of the macro-zooid, divides once (D) and the abortion of one of its products, or gametes $\left(d^{2}\right)$, has already been commented upon, and the obvious reasons given.

At the time of writing the present paper it is quite out of question to construct diagrams from Maupas' accounts of the conjugation of other forms, which he has studied, but of which he has furnished no schemes. And the risk must be taken of postponing another study of the whole of his immense monograph, until more leisure is available. It might well happen that some details of the explanation of his results here suggested may have already been put forth by Maupas himself. If so, there is neither wish nor intention of detracting from his merits. What has really been my concern was the demonstration of an antithetic alternation of generations and of a spore-formation with reduction in the 


\section{Beard.-Reproduction in Animals and Plants.}

Infusoria. All else has only been offered in order to convince the reader of the inherent probability of the truth of the attempted solution. This is certainly new, and Maupas could not have entertained the slightest idea of it. This is certain from the general discussion in his memoir.

Before the close of my remarks on the conjugation of the Infusoria, I should like to quote a passage from R. Hertwig and express entire agreement with it. As against Maupas on p. 2 I4 of his work on Paramecium Hertwig writes : 'Bei den meisten Infusorien copuliren weder sexuell differenzirte Kerne, noch auch Kerne sexuell differenzirter Thiere, sondern gleichwerthige Kerne, welche in gleichwerthigen, aber getrennt und unabhängig von einander entwickelten Thieren entstanden sind. Damit fehlt aber die Basis für die Begriffe männlich und weiblich, vollends aber für den Begriff Hermaphroditismus.'

It is doubtless highly hazardous on the part of a zoologist to venture an opinion that the botanists may, nay, must be, in error in supposing spore-formation to be a later acquisition than sexual reproduction.

We are bound to assume it to be a primitive process, which had its origin in the necessity of reduction following a conjugation ${ }^{1}$.

The primitive form of 'sexual' reproduction or conjugation-and by either of these terms may be understood the

1 Another, and perhaps better, way of stating this would be that an antithetic alternation of a very simple kind must be a consequence of even the most primitive conjugation in plants also. That a suspicion of an alternation of generations with spore-formation is more than justified even in the simplest plants is proved by the facts of the conjugation of Closterium, as described by Klebahn. After the conjugation of like gametes, the resulting zygote, i.e. its duplicated nucleus, divides twice without resting-phase. Four nuclei arise, two in each cell as there is only one fission of the protoplasm of the zygote. As described by O. Hertwig (Die Zelle und die Gewebe, pp. 224, 225) ' the two nuclei of each (of these cells) rapidly acquire a different appearance, the one becomes large and vesicular, whilst the other remains small and later on disappears.' This is strongly reminiscent of the ' pole-nuclei' of the Infusorians, indeed, these abortive nuclei must be regarded as exactly the equivalents of the latter. The process is, without question, a sporeformation with reduction. Of the spores formed two are abortive. Thus here also the antithetic alternation would appear to obtain. 
union of at first like zygotes, and afterwards of unlike but none the less morphologically equivalent ones-apart from fission, was from its very nature bound up with an asexual process, or spore-formation, leading to reduction of the previous duplication of chromosomes. This very primitive antithetic alternation of generations still exists, and is bound to remain in a more or less modified form in both animals and plants, in consequence of the duplication which results from any conjugation. The tendency in higher forms has been in the direction of its modification, never towards its entire suppression. An attempt is made to abolish one of its most obvious factors, spore-formation, in both Infusoria and Metazoa. In the former this results in the formation of functionless vestigeal spores, but the fact of a spore-formation is very evident, for these are here necessary factors in the evolution of conjugating gametes.

In Metazoa it has been avoided by apospory. The processes differ considerably in the two cases, because the lines of evolution have been so divergent. But, although the means adopted to attain the end (i.e. reduction of the duplicated number of chromosomes), is not by any means identical in both, the result is the same, the attainment of cells (nuclei), in which the primitive or reduced number of chromosomes is present. In the one case the reduction is associated with the formation of abortive spores (pole-nuclei), in the other with abortive eggs, i.e. abortive gametes (polar bodies).

Even in the steps leading to the spore-formation abortive products may be formed, as in Onychodromus grandis, where, in addition to abortive spores, functionless, and therefore abortive, spore-daughter-nuclei obtain (woodcut $12 b$ ).

The same form is also interesting as presenting at the close of the division $\mathrm{D}$ a number of abortive gametes, which are to be regarded as in a certain sense the homologues of the 'polar bodies' of Metazoan oogenesis. Similar abortive gametes are also present at the corresponding stage in Vorticella.

Boveri has shown that the 'polar bodies' of Metazoa 


\section{Beard.-Reproduction in Animals and Plants.}

represent abortive eggs. It has now been proved that in the Infusorian conjugation abortive spores are invariably, and abortive gametes occasionally, formed.

It also follows that the essential act of conjugation, apart from the spore-formation and other processes leading up to the formation of like gametes, is the same in both Protozoa and Metazoa ${ }^{1}$, i. e. the union of two like nuclei, not, as is often stated, two like half-nuclei.

Finally, from all that has been adduced in the course of the discussion, it may be concluded that there is one universal law underlying all those processes (conjugation, fertilization), which are classed together as sexual in nature, and this law has been defined in the preceding pages.

\footnotetext{
1 And in plants.
} 


\section{$2 \mathrm{BHL}$ Biodiversity Heritage Library}

Beard, J. 1895. "On the phenomena of reproduction in animals and plants. The conjugation of the infusoria and the meaning of the processes involved." Annals of botany 9, 456-468.

https://doi.org/10.1093/oxfordjournals.aob.a090750.

View This Item Online: https://www.biodiversitylibrary.org/item/233478

DOI: https://doi.org/10.1093/oxfordjournals.aob.a090750

Permalink: https://www.biodiversitylibrary.org/partpdf/318389

\section{Holding Institution}

Smithsonian Libraries

\section{Sponsored by}

Biodiversity Heritage Library

\section{Copyright \& Reuse}

Copyright Status: Not in copyright. The BHL knows of no copyright restrictions on this item.

This document was created from content at the Biodiversity Heritage Library, the world's largest open access digital library for biodiversity literature and archives. Visit BHL at https://www.biodiversitylibrary.org. 